\title{
Strain rate and temperature effects on crack initiation of direct aged 718 Alloy
}

\author{
Maxime Perrais $^{1,2, a}$, Anthony Burteau ${ }^{1}$, Alexandre Seror ${ }^{1}$, Dominique Poquillon $^{2}$, and Eric Andrieu ${ }^{2}$ \\ ${ }^{1}$ SNECMA, Site de Villaroche, Rond-Point René Ravaud, 77550 Moissy-Cramayel, France \\ 2 CIRIMAT, INP-ENSIACET, 4, allée Emile Monso, BP. 44362, 31030 Toulouse Cedex 4, France
}

\begin{abstract}
During mechanical tests at high temperature in an oxidizing atmosphere, the effects of strain rate on crack initiation are noticeable. This effect is due to a coupling between local mechanical loading and oxidation. Samples were machined in a turbine disk made of direct aged alloy 718. Tests were performed to understand the effect of these couplings on crack initiation and to ensure lifetime is optimized. This study compared the cracking resistance of two different specimen geometries at a given plastic strain and performed quantitative measurement of the mechanical loading conditions inducing crack initiation between $600^{\circ} \mathrm{C}$ and $650{ }^{\circ} \mathrm{C}$. Sample geometries consisted in tensile flat specimens and $\mathrm{V}$-shaped samples. This specific geometry was used to localize strain and damage in the apex of the $\mathrm{V}$ and to reach strain rates lower than those possible on standard specimens. Digital image correlation technique was used to provide strain measurements. For each temperature and strain rate, finite element calculations using the identified constitutive law were performed to get a refined level of strain in different areas at the $\mathrm{V}$ apex. Tests were stopped after an imposed displacement corresponding to a given plastic strain distribution. SEM observations of the surface of the flat tensile samples revealed no crack initiation. On the contrary, SEM observations at the apex of V specimens for which the level of cumulative strain was close to the level of cumulative strain of flat samples reveal the presence of intergranular damage when the strain rate used was below a given level.
\end{abstract}

\section{Introduction}

Alloy 718 is a nickel-base alloy used for many different applications in fields including aerospace, chemical, nuclear engineering. This study concerns one of its aeronautical application: low pressure turbine disk of aircraft engine. This part of the engine is submitted to high temperature and high stress level. The break of this engine part during a flight is not acceptable due to the high speed of rotation and the mass of the disk. To improve design and lifetime, a better understanding of crack initiation mechanisms is very important.

In this study, all tests are carried at $600{ }^{\circ} \mathrm{C}$ and $650{ }^{\circ} \mathrm{C}$ under laboratory air. The purpose is to check the effect of the strain rate (down to $10^{-6} \mathrm{~s}^{-1}$ ) on damage initiation on direct aged 718 alloy.

The approach which is used in this work is to realize tensile tests on two different sample geometries and at different strain rates. Samples are carefully polished and observed before each test to check their initial surface state. Tests are stopped at a given cumulated strain and then damage initiation is observed. In the first part of the article, material and experimental procedures are detailed. Then the results of the mechanical tests and SEM observations are presented and discussed.

\footnotetext{
${ }^{a}$ Corresponding author: maxime.perrais@ensiacet.fr
}

These results give us a constitutive law and serves as a mechanical reference for each temperature. To observe damage, V shaped specimens are used. These specimens have a geometry which is favorable to initiate crack with lever effect. Thanks to this $\mathrm{V}$ geometry, a comparison of damage between several strain rates will be achieved. This geometry can realize, with a standard tensile device, slower tensile test. The damage will be observed with SEM.

To estimate the level of accumulated strain, a finite element calculation will be used on the V shaped geometry. Calculations are carried out by constitutive law and test parameters as strength and displacement of tensile device. To check those calculations, images correlation method is used and total strain in the apex of the $\mathrm{V}$ are recorded.

\section{Material and experimental procedures}

The investigated 718 alloy comes from a forged disk. This forged disk is direct aged and its chemical composition is described in Table 1. "Direct aged" heat treatment consists in applying the precipitation heat treatment directly after the forging step, without solution annealing.

Depending on the location on the disk, the grain size number is between 9 and 11 ASTM for all samples of this study. To sample specimens from the disk, electrodischarge wire cutting is chosen to minimize the loss of matter and to provide a good geometric precision. This point is very important especially with $\mathrm{V}$-shaped specimen 
Table 1. Chemical composition of 718 alloy (weight \%).

\begin{tabular}{|l|l|l|l|l|l|l|}
\hline $\mathrm{Ni}$ & $\mathrm{Cr}$ & $\mathrm{Fe}$ & $\mathrm{Nb}$ & $\mathrm{Mo}$ & $\mathrm{Ti}$ & $\mathrm{Al}$ \\
\hline 50 & 17 & Bal. & 4.75 & 2.8 & 0.65 & 0.2 \\
55 & 21 & & 5.5 & 3.3 & 1.15 & 0.8 \\
\hline
\end{tabular}
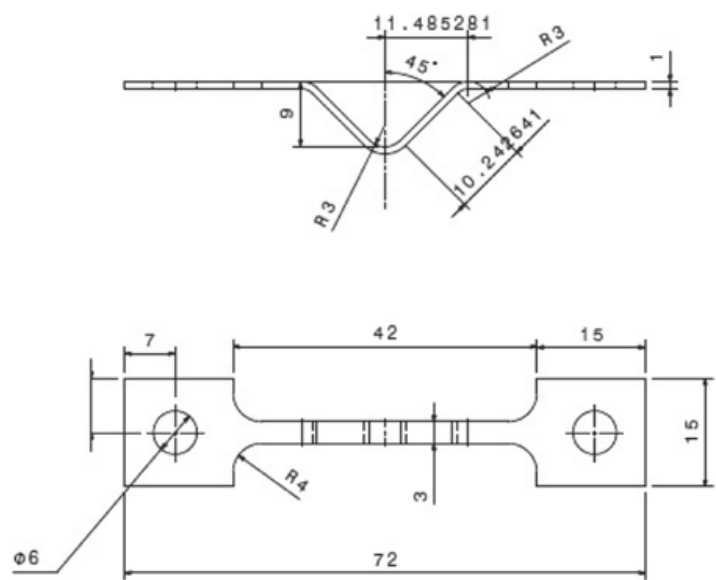

Figure 1. Sketch of V-shaped specimens.

(cf. Fig. 1). V-shaped specimens have a geometry which enables us to reach lower strain rates than flat samples and to localize strain and damage. This geometry was initially proposed by Totsuka and al. [1,2] and enabled stressing of the sample surface. It has already been used on nickel based alloys $[3,4]$ to get a better understanding of crack initiation.

Flat geometry has been tested for three strain rates $\left(10^{-3} \mathrm{~s}^{-1}, 1.2510^{-4} \mathrm{~s}^{-1}\right.$ and $\left.1.2510^{-5} \mathrm{~s}^{-1}\right)$, minimum value possible on the experimental device) and two temperature $\left(600^{\circ} \mathrm{C}\right.$ and $\left.650^{\circ} \mathrm{C}\right)$. These tensile specimens have the following dimensions: $1 \mathrm{~mm}$ thickness, $3 \mathrm{~mm}$ width and the gauge length is $32 \mathrm{~mm}$. Those tests give us a behavior law which is used to perform finite element calculation with an isotropic elastic plastic law. This law is an approximation as viscoplastic behavior is neglected but for our needs, it's enough to estimate strain and stress states in the $\mathrm{V}$ shaped specimens.

For the V-shaped specimens, twelve samples have been tested. For each one, a maximal displacement of $5 \mathrm{~mm}$ was imposed. Like flat specimen, three strain rate and two temperatures $\left(600^{\circ} \mathrm{C}\right.$ and $\left.650{ }^{\circ} \mathrm{C}\right)$ are used. The highest strain rate is similar to standard tensile test. Two others are respectively one and two decade bellow this "standard strain rate" (about $10^{-4} \mathrm{~s}^{-1}$ ).

Before tensile tests, it is necessary to prepare carefully the surface of the specimens. The surface modified by machining is carefully removed using successive polishing's up to 2400 -grit $\mathrm{SiC}$ paper. The purpose is to remove the zone affected by machining but also to get a surface state that enables us to observe crack initiation.

The tensile device is an MTS Electromechanical Test Machine with a $5 \mathrm{kN}$ load cell. The apparatus is equipped with a furnace using six halogen radiation lamps to heat the sample. Three thermocouples are spot-welded on the sample to control and regulate the temperature of this three zones radiation furnace. A PID controller is used for the temperature regulation of these three areas. This system allows temperature gradient lower than $5^{\circ} \mathrm{C}$ for both geometries. Samples are pre-heated before the tensile tests in order to get stabilized temperature not only in the sample but also in the grips. The crosshead displacement is then imposed at a given rate.

For standard tensile specimens, the deformation of the gauge length is measured with an optical micrometer. This micrometer measures the distance between two alloy 718 flags spot-welded on the specimen delimiting the gauge length. This monitoring using real strain measurement allows us to stop the test at the value of $2 \%$ of total strain.

For the tensile tests carried out on the V-shaped sample, it is necessary to calculate the local strain field to know the load path on the interest area. These calculations are performed using Cast $3 \mathrm{~m}$ finite element code [5]. The finite element model is based on an elastic plastic isotropic constitutive law which has been identified thanks to standard tensile test $\left(10^{-4} \mathrm{~s}^{-1}\right)$.

For each V-shaped sample, dimensions of the simulated V-shaped geometry are adjusted on real specimen dimensions measured after the polishing step. Calculations take into account the symmetry of the specimen and are carried out in 2D using plane strain hypothesis. Two boundary conditions are defined. The $\mathrm{X}$ displacement of symmetry axis in the $\mathrm{V}$ apex equals zero. A load is imposed on the head of $\mathrm{V}$ sample. Thanks to that, the strain in the apex of the $\mathrm{V}$ can be calculated as well as the displacement of the extremity of the sample. This allows us to be able to interrupt the test when the target strain is reached in the apex of the $\mathrm{V}$ submitted to tensile condition due to the stretching of the V. Furthermore, the local strain rate can be calculated by linking the calculated strain and the corresponding experiment duration [3].

\section{Results}

At first, a comparison is carried out between experimental and calculated macroscopic curves. Macroscopic curve represent the strength imposed on $\mathrm{V}$ sample versus the crosshead displacement of traction machine.

At $600{ }^{\circ} \mathrm{C}$ and for the 3 ranges of strain rate, these curves are shown on Fig. 2.

This wavy form is due to the $\mathrm{V}$ geometry which the plastic strain is not uniform ( $c f$. Fig. 3).

Nevertheless it's allowed a comparison between experience and simulation. Considering that only elastoplastic behavior is taken into account in the constitutive law, the correlation between experience and simulation is quite satisfactory. Nevertheless an effect of creep is noticeable especially for $10^{-6} \mathrm{~s}^{-1}$ curve.

The same tendencies are observed at $650^{\circ} \mathrm{C}$. The creep behavior is also evidenced.

As macroscopic load/displacement curves are in good agreement, we can reasonably trust the calculations to estimate the plastic strain in the apex of the V: $8 \%$ for five millimeters of stretching. Actually, a gradient of strain is imposed on the area of interest. This calculated plastic strain gradient, shown on Fig. 3, is between $8 \%$ and $2 \%$. Calculations at $650{ }^{\circ} \mathrm{C}$ are performed with the same method. 


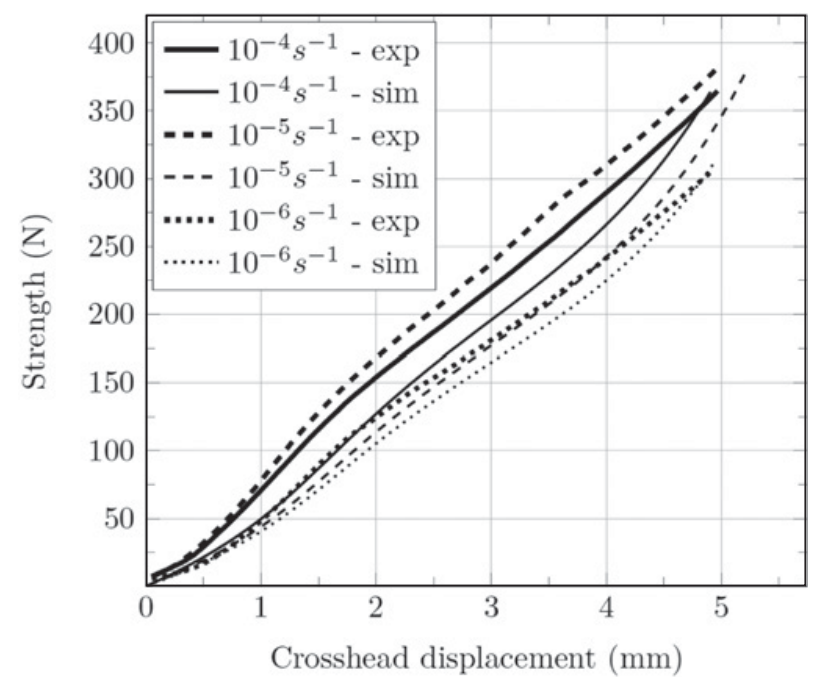

Figure 2. Macroscopic behavior of $\mathrm{V}$ shaped specimen at $600^{\circ} \mathrm{C}$.

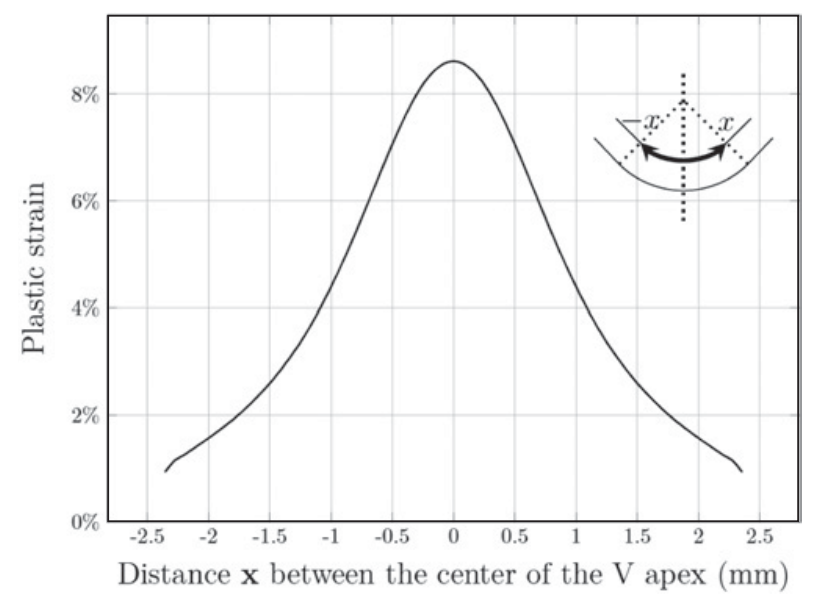

Figure 3. Calculated gradient of plastic strain imposed on area of interest after $5 \mathrm{~mm}$ of $\mathrm{V}$ stretching at $600^{\circ} \mathrm{C}$ and $10^{-5} \mathrm{~s}^{-1}$.

After mechanical tests, SEM observations are performed to visualized damage. These observations are focus on the intrados of the $\mathrm{V}$, which is the preferential area of damage for $\mathrm{V}$-shaped specimen. Each crack initiation, or crack propagation out of a precipitate is localized and measured. We record if these crack initiations are or are not linked to a carbide/carbonitride (cf. Fig. 4). Thanks to this method, for each test, two data are obtained: the number of cracks and the fraction of cracks linked to a precipitate.

On Fig. 5, results for two temperature and three strain rates are represented. The crack initiations are counted on a $5 \times 3=15 \mathrm{~mm}^{2}$. At $600^{\circ} \mathrm{C}$, the slower strain rate, the more cracks initiate.

At $650{ }^{\circ} \mathrm{C}$, no clear tendency is observed.

On Fig. 6, two temperature and three strain rates are analyzed. For all these tests, the fraction of cracks linked to a carbide/carbonitride is larger than $80 \%$ except for the two tests performed at $600^{\circ} \mathrm{C}$ and $10^{-6} \mathrm{~s}^{-1}$. In this case, the fraction of cracks linked to a carbide/carbonitride decrease to about $50 \%$.

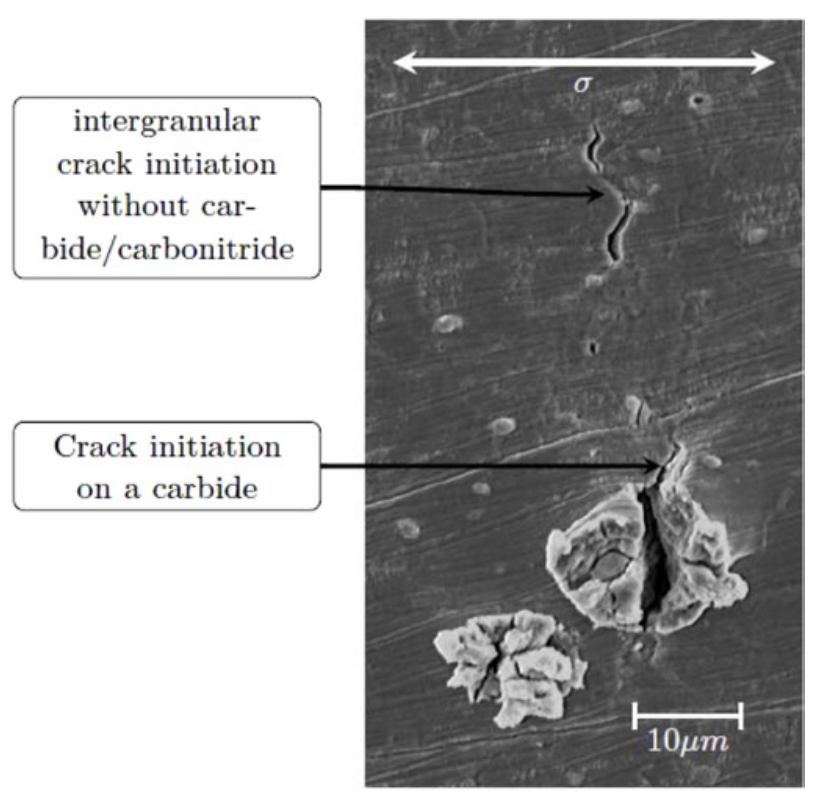

Figure 4. Cracks on a carbide and inside the Ni matrix $\left(650^{\circ} \mathrm{C}\right.$, $10-6 \mathrm{~s}-1,8 \%$ plastic strain).

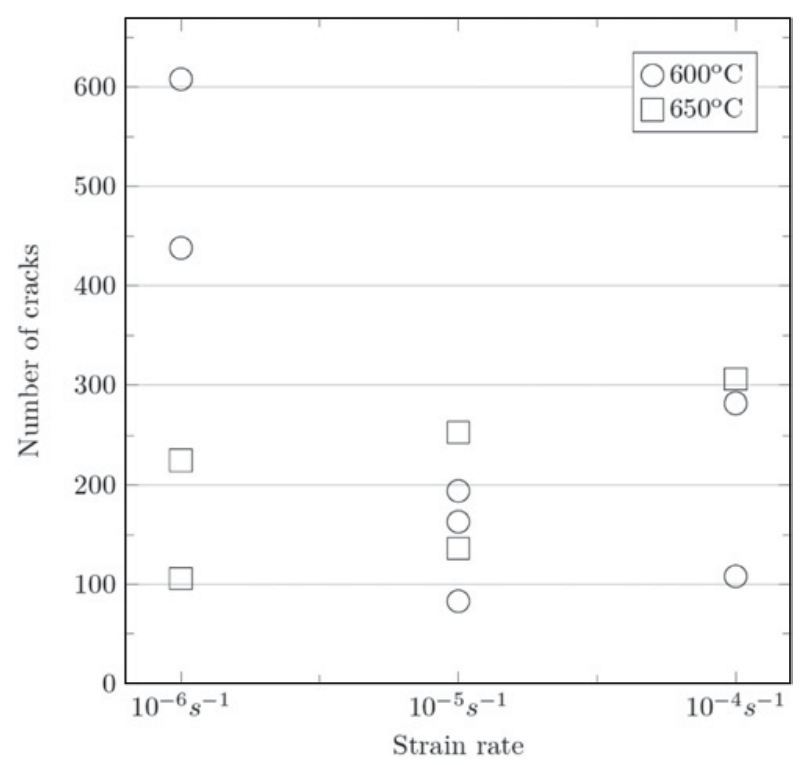

Figure 5. Synthesis of the number of cracks versus strain rate.

\section{Discussions}

The macroscopic load/displacement curves show a strain rate effect. In this range of temperature $\left(600^{\circ} \mathrm{C}-650^{\circ} \mathrm{C}\right)$, 718 alloy behavior is viscoplastic, creep occurred [6,7].

However, we have chosen to use the stress-strain curve obtained at standard strain rate as an elastic plastic isotropic constitutive law for finite element computations.

Digital image correlation (ARAMIS software) has been used to control the calculated values of total strain in the apex of the $\mathrm{V}$.

For the tests carried out, the measured strains were in good agreement with the calculated only for the larger strain rate.

However, due to creep, calculations tend to slightly underestimate non-elastic strain for the smaller strain rates. 


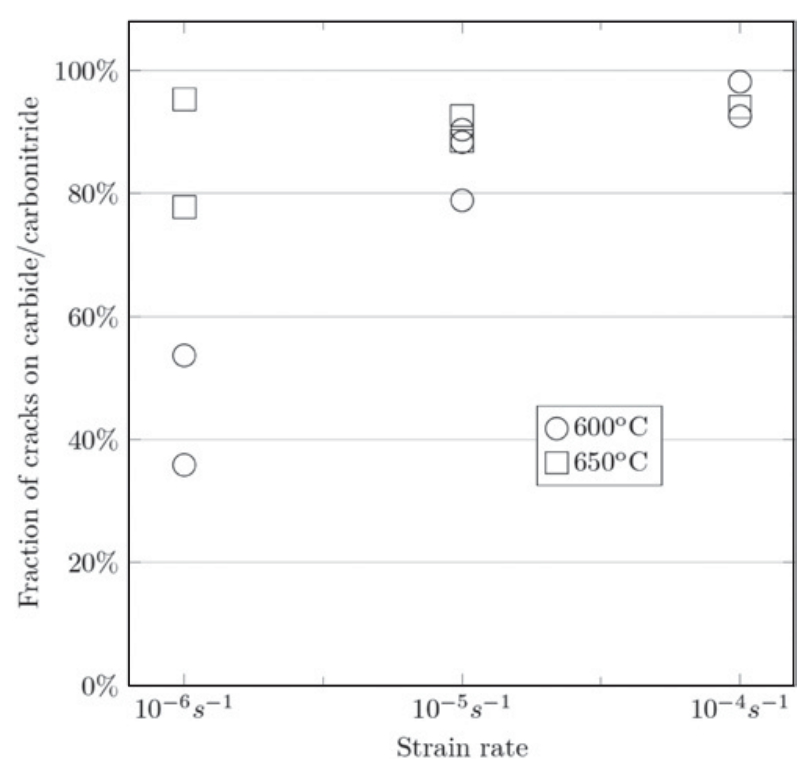

Figure 6. Fraction of cracks linked to carbide/carbonitride versus strain rate.

The tests carried out at slow strain rate at $600^{\circ} \mathrm{C}$ $\left(10^{-6} \mathrm{~s}^{-1}\right)$ induce a significant crack initiation not correlated with carbide or carbonitride. This tendency is less obvious at higher temperature $\left(650^{\circ} \mathrm{C}\right)$ or at higher strain rate.

Additional tests carried out for smaller imposed displacement (only $2.5 \mathrm{~mm}$ ) corresponding to smaller plastic strain revealed that crack initiation are then located mostly on precipitates.

The appearance of intergranular crack at $10^{-6} \mathrm{~s}^{-1}$ is linked to a sufficient inelastic strain level and to a sufficiently slow strain rate this behavior, reported only for tests carried out under air, has already been noticed [3,8-10].

Authors linked this specific intergranular crack initiation to dynamic strain ageing (DSA).
However, crack initiation due to carbide or carbonitride are widely reported $[9,11]$, and especially for fatigue tests on 718 Alloys.

\section{Conclusions \& prospects}

This study combines V-shaped specimens and FE model to explore a large range of strain rates. Thanks to this specific geometry, damage initiation has been observed. Tests with and without oxidation conditions are to be carried out to check damage mechanisms. Different loading path on $\mathrm{V}$ shaped specimen could be a solution to control the damaging.

The authors would like to thank Ronan Mainguy and Jean Claude Salabura for their assistance on test devices.

\section{References}

[1] N. Totsuka, Z Szklarska-Smialowska, Corrosion 43, 734 (1987)

[2] N. Totsuka, E. Lunarska, G. Cragnolino, Z SzklarskaSmialowska, Corrosion, 43, 505 (1987)

[3] B. Ter-Ovanessian, D. Poquillon, JM. Cloué, E. Andrieu, Mat.Sci.Eng., (2011)

[4] J. Deleume, D. Poquillon, V. Garat, JM. Cloué, E. Andrieu, Corr. Sci, 50,737 (2008)

[5] Cast3m : http://www.cast3m.cea.fr

[6] A. Thomas, M. El-Wahabi, JM. Cabrera, JM. Prado, J.Mat.Proc.Tech, 177;469 (2006)

[7] JW Brooks, PJ. Bridges, TMS Superalloys (1988)

[8] E. Andrieu, R. Cozar, A. Pineau, TMS Superalloys 718 and derivatives (1989)

[9] L. Fournier, D. Delafosse, T. Magnin, Mat.Sci.Eng, 316, 95 (2001)

[10] V. Garat, JM. Cloué, D. Poquillon, E. Andrieu, Jour.Nuc.Mat, 37595 (2008)

[11] S. Deyber, F. Alexandre, J. Vaissaud, A. Pineau, TMS Superalloys 718 and derivatives (2006) 